\title{
The NMR structure of the NIPP1 FHA domain
}

\author{
Hiroyuki Kumeta Kenji Ogura Souichirou Adachi $\cdot$ Yuko Fujioka \\ Nobuhiro Tanuma $\cdot$ Kunimi Kikuchi $\cdot$ Fuyuhiko Inagaki
}

Published online: 15 February 2008

(C) Springer Science+Business Media B.V. 2008

Erratum to: J Biomol NMR

DOI 10.1007/s10858-008-9222-x

The fifth author's name was misrepresented in the original publication.

The online version of the original article can be found under doi:10.1007/s10858-008-9222-x.

H. Kumeta · K. Ogura · S. Adachi · Y. Fujioka · F. Inagaki ( $\square)$

Laboratory of Structural Biology, Graduate School of

Pharmaceutical Sciences, Hokkaido University, Sapporo,

Hokkaido 060-0812, Japan

e-mail: finagaki@pharm.hokudai.ac.jp

N. Tanuma $\cdot$ K. Kikuchi

Division of Biochemical Oncology and Immunology,

Institute for Genetic Medicine, Hokkaido University,

Sapporo, Hokkaido, Japan 